\title{
Appliances Used and Methods ADOPTED FOR CLEARING THE LINE AFTER DERAILMENTS AND ACCIDENTS.
}

Paper read before the Institution by F. G. MOORE, Member, Accrington, at Manchester, on 7th January, and at Leeds, 8th February, 1921.

Paper No. 93.

The subject with which the Author has to deal is one which will appeal to anyone interested in the locomotive in particular and railway work in general. The nature and causes of derailments are legion, therefore it is proposed to briefly outline a number of examples of those usually to be met with, and to describe the appliances used and the methods adopted in dealing with the same.

Derailments may be divided into several distinct groups, and the methods adopted for clearing the line under the circumstances peculiar to each may reasonably be said to be the same in most instances.

Collisions Head-On.-It is usual to find considerable damage to the iocomotives concerned, telescoping of rolling 
stock if passenger trains are involved, and piling up and overturning of vehicles in the case of goods trains.

Collisions at Junctions.-The damage in such cases will vary according to the angle of impact. If the collision occurs at anything approaching a right angle, one of the trains will be cut through and piling up and overturning of vehicles will be the result. On the other hand, if the angle of impact be fairly acute, a more or less glancing blow will be struck. It is extremely probable that both locomotives and many of the vehicles of the trains concerned will be overturned and badly smashed. This latter form is usually the most difficult derailment with which one has to contend, as in such cases, and especially if the mishap should occur in a cutting, all the running lines will be completely blocked. The head-on collision as a general rule is responsible for greater loss of life due to the telescoping of the rolling stock.

Break-Looses and Runaways.-These, of course, occur. on a gradient, the first being due to fracture of some portion of the draw gear, the latter by carelessness on the part of the person or persons responsible for efficient braking of the stock standing on a falling gradient. The result is the same; the vehicles run back to the trap points, are there derailed, and eventually come to rest at the bottom of an embankment or pile up in a cutting, as the case may be. If no trap points are encountered, the first obstruction in the shape of bufferstops, standing vehicles or train will bring the runaways to rest, and damage and piling up will be the result.

Split Points.-The most common form of derailment known. The causes are carelessness on the part of the persons responsible for seeing that the points are fitting closely before allowing vehicles to pass over them, or otherwise wear and tear of the permanent way. The extent of the derailment in these cases is generally governed by the speed at which the vehicles are travelling when the mishap occurs.

Buffer-Locking.-Usually caused by rough handling of the stock during shunting operations. In most instances the wagons are not derailed, or perhaps one or two out of a dozen or so may be off the road with one pair of wheels. It is generally found that empty wagons situated between loaded ones are the ones to be derailed.

Miscellanenus.-Quite a number may be grouped under this heading. Trains or vehicles may be derailed at curves when running at a high rate of speed, or the more rare cases where the derailment may be due to the distortion of 
the permanent way; or again, obstructions may be deliberately placed on the line by persons of evil intent. Failure of some part or parts of the locomotive or vehicles, such as broken and displaced springs, brake gear, etc., may fall and cause an obstruction and eventually a derailment. Packages falling from wagons due to faulty loading also have to be reckoned with. There are many others, but time is too short to describe them all.

Equipment of Breakdown Trains.-The breakdown train should consist of five vehicles, a six-wheeled van at each end, crane-truck, bolster wagon and runner wagons. One of the vans is used to carry the tools; the other is divided into two compartments-one for the store of wood packing, the other for the accommodation of the men. On the crane bolster wagon are four lockers in which are carried a variety of sling and other chains. These lockers are distinctly labelled showing the contents of each. On the runner wagon is carried a spare standard bogie. There is a receptacle at each end, one containing ramps and the other the oxy-acetylene cutting plant with spare gas cylinders for same. To be found in the tool van is an assortment of hydraulic jacks of various lifting capacity, screw jacks of various lengths and shapes, slewing tackle, stretching screws, saws for timber and metal, axes, picks, spades, punches, chisels, bars, two complete sets of single and double-ended spanners, various taps, stocks and dies, heavy and light hammers, bench and vice, and many other small tools too numerous to mention. Apart from all these, there is usually to be found a number of specially-made appliances for dealing with different awkward jobs which may crop up. A number of acetylene flare-lamps, drums of calcium carbide for the same, an assortment of oil torch-lamps, ambulance material and fire-extinguishing apparatus, may be said to complete the outfit. The great things to be aimed at when equipping a modern tool van are accessibility and, wherever possible, visibility. To attain this desirable end it is usual to carry the hydraulic and other jacks along the sides of the van floor, leaving a clear passage from end to end of the van. Small tools, jack handles, bars and punches are accommodated in clips and racks attached to the van walls. A length of flat bar iron raised one inch above the floor level should run from end to end of the van; heavy jacks, etc., may be balanced on this and easily made to slide to and from their places when required.

Swing jibs should be provided at the van doors of sufficient length to enable the jacks to be lifted from the centre and swung outwards clear of the van steps and lowered 
to the ground by means of rope or chain blocks hung from the jibs. The storage of wood packing should receive careful attention. This should, where practicable, be fitted in cages properly labelled and arranged in consecutive sizes. This packing cage should contain that packing which is most used for following up hydraulic jacks, and should be placed opposite the double doors of the packing van so as to be readily accessible when required. In the packing van wire cables, snatch blocks, a mono-rail trolley for the rapid transport of heavy packing, jacks, etc., may be carried. (Fig. 4).

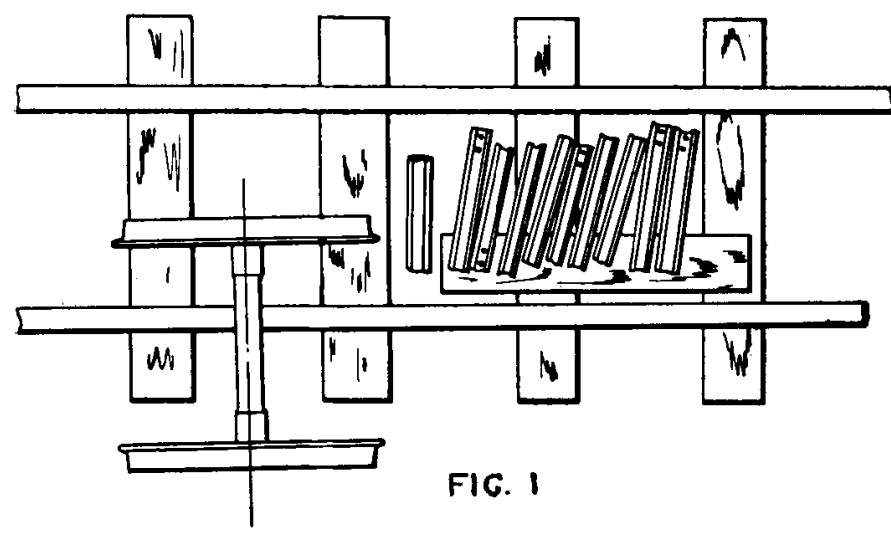

The Breakdown Gang.-The composition of the breakdown gang depends upon the location of the train and ts equipment. The number usually told off is twelve, one man being held responsible for the care of the train-cleaning, keeping in good working order, issuing the checking of all appliances kept therein. All broken and damaged tools should be replaced or repaired immediately the train returns to the shed. The gang will include two or three fitters, a blacksmith, and a few handy labourers. Where a steamcrane is stationed it is the practice to have a gang of men specially told off, the driver of the crane, another man capable of acting in that capacity, and four men accustomed to the fixing of chains and slings, fixing of rail clips, packing of crane girders, etc. These men should regularly perform the same duties, so that no time is wasted in having to give instructions to them in regard to minor details; with continual practice such matters will be attended to by the men on their own initiative. The same methodical working should characterise the whole gang. To see a really well-trained 
gang at work is a pleasure. The quiet, deliberate conduct of an efficient, well-trained gang stands out in sharp contrast to the haphazard methods common to a scratch team of undrilled men. Within recent years the introduction of highcapacity steam travelling cranes has done much to render the work of a breakdown gang less arduous and difficult than formerly. When the use of cranes is impracticable and dragging and ramping cannot be resorted to, then use must needs be made of lifting jacks-a slow job under the most favourable circumstances.

Having arrived on the scene of the derailment, the man in charge of the breakdown gang should make a careful survey of the position of the derailed vehicles and, if possible, ascertain the cause of the mishap. The latter is not always an easy matter, due to the confusion and disonder which usually prevail as a result of the accident. Assuming there has been no loss of life, the mode of procedure should be quickly decided upon and the foreman of the gang clearly instructed as to what is required. The saving of time must in all cases be the first consideration, and where main lines are blocked, further damage to stock or permanent way should not be considered but the line cleared with the least possible delay, If steam-cranes are not immediately available, resort must be made to dragging and ramping, and all possible in the way of clearing the line should be carried out by this means until the steam-crane arrives, assuming the same to have been sent for. If the mishap should eccur on an embankment, the quickest method of disposing of the derailed stock will be by throwing them down the embankment and leaving them there until some favourable opportunity occurs for loading them up. In a cutting, however, the derailed vehicles cannot be so easily disposed of, therefore in such an event it is necessary to concentrate one's energy on the clearing of the line least blocked and to enable the traffic people to put single line working into operation as quickly as possible. In the absence of a steam-crane the use of lifting jacks, hand-cranes and other slow means of rerailing vehicles should not be resorted to until all possible has been tried in the way of dragging and ramping.

Unfavourable Position of Breakdown Train.-It of ten happens that it is not possible to have the breakdown train in close proximity to the scene of the mishap. In such cases the rapid transport of heavy tools and material must receive consideration. This is best accomplished by the use of a portable mono-rail bogie. 
Ramping of Vehicles.-The secret of success in the use of ramps is to make sure that they are thoroughly secure and solidly packed; if such precautions are not taken time will inevitably be wasted in releasing the displaced ramps. The best form of ramp is one, the lugs of which extend below the bottom edge of the rail and are slotted to receive a cotter which draws them tightly to the rail. Such ramps require little or no packing whatever, providing the cotter is tight. A most useful appliance is the half or single ramp; no tool van should be without a set of four of these-two inside and two outside pattern. These half-ramps can be used where checkrails or any other peculiarity of the permanent way altogether preclude the use of a double or full ramp. There is no reason why any vehicle and many locomotives (electric stock excepted) which are derailed and come to rest without overturning should not be rerailed by means of ramps. Provided the vehicle comes to rest in an upright position, even though it may be a considerable distance from the rail, it may by supplementary means be eventually dragged to a position favourable to ramping.

Supplementary Means as an Aid to Ramping.-The original method of attaining this object was by first coupling up the engine to the derailed vehicle by means of a chain and calling upon the gang to push at the off leading corner of the vehicle. After some distance had been traversed and a foot or so of ground gained, the engine was uncoupled and a shorter coupling inserted. This process was repeated until the wheels were sufficiently near to the rails to mount the ramps. A better method is to construct an inclined plane (Fig. I) consisting of short scrap lengths of rail, one end of which is pushed into the ballast and the other supported on a piece of hard timber packing; a long wedge of timber is placed against the flange of the inside wheel and as short a coupling as possible inserted. When pulled up, the wheel mounts the wedge and slides down the inclined plane to the required position at one operation, ramps are inserted and the vehicle rerailed. Where it is necessary to put the wheel of a vehicle at the other side of the rail to that at which it has come to rest is most readily accomplished by the use of a half-ramp.

Use of Wire Cable and Snatch Block.-The wire cable and snatch block may be used for dealing with overturned vehicles. In such cases it is usual to pass a chain or chains round the body of the vehicle, hooking up to any convenient part of the under-frame, and then couple up to the wire 
cable attached to the drawhook of the engine and pull until the vehicle assumes an upright position; afterwards rerail with ramps as before described. If, however, the vehicle should be without wheels and it is not convenient to load it up immediately, this operation may be repeated and the vehicle rolled until it is out of the way. If necessary to use a snatch block in conjunction with the cable, the locomotive would be placed on an adjacent road and the snatch block attached by means of chains or clips to the running rail.

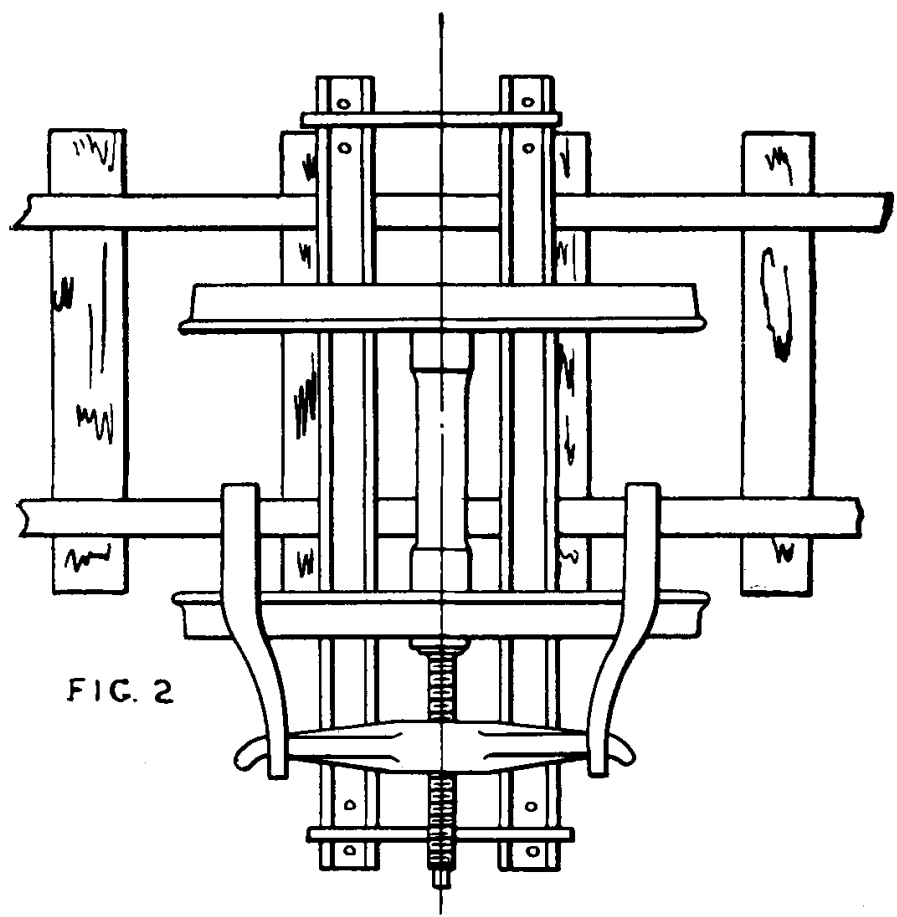

This method is quite effective for rolling wagons up embankments for loading up with a hand-crane when the crane is not capable of raising the damaged stock due to shortness of jib, etc.

Temporary Rail Tracks.-Where a locomotive is derailed and one end is a considerable distance from the rails it is not unusual to lift the engine at each end and lay down a temporary track of old rails, and lower the engine on to this track and afterwards make use of ramps; these old rails 
should be laid on their sides, and when possible secured to the sleepers by spikes passed through the fishplate boltholes. This may be applied where an engine is derailed at trap points.

Use of Scrap Ballast, etc., for Vehicles Derailed at Points.- In the event of an engine or vehicle being derailed due to running between the points it may readily be rerailed by filling up the space between switches and the stock-rail with broken packing, ballast, lengths of rail, etc., and drawing the engine back in the opposite direction. It is advisable in such cases to uncouple the points and to remove the point rods in order to allow free movement in either direction to the switches. Precaution should also be taken to strap the rails together between which the wheels will run. This is best carried out by rail clips of various lengths passed under the rails and secured with an ordinary chair key (Fig. 3).

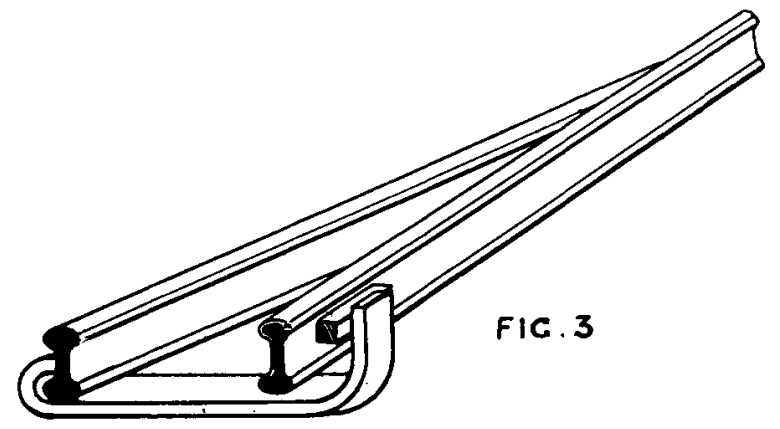

Bogie Vehicles.-Derailed bogie vehicles are usually very difficult to deal with by means of ramps, owing to free movement of the bogie on the centre pin; the least obstruction is sufficient to deflect the wheel from its intended course, and it fails to mount the ramp in consequence. If the derailed wheels are some distance from the rail, the surest method is to secure the bogie to the under-frame by means of specially made slings and to lift the vehicle at one end with a crane or, failing this, with hydraulic traversing jacks.

To Re-Rail an Engine by Means of Lifting and Sleuing. -The engine is lifted above rail level at one end by means of jacks, and the wheels are rested on iron plates well packed on hard timber. The wheels are then scotched, and the other end of the engine is lifted and lowered on to a pair of steel rails about $\mathrm{I} 2 \mathrm{ft}$. in length and secured $\mathrm{I} 5 \mathrm{in}$. apart by strong links passed over the ends of these rails. A chain carrying 
a suitably bent plate to accommodate a double forcing screw is then linked up to the stock-rail.

The forcing screw is placed between the plate carried by the chain and the wheel tyre. The engine is then slewed across the rails to the desired position. A hydraulic jack is inserted under the buffer-beam, the slewing tackle is removed, and the engine rerailed at one end. The other end is then lifted clear of the slewing plates; a short traverse of the jack is then made, the jack lowered, and the engine rerailed.

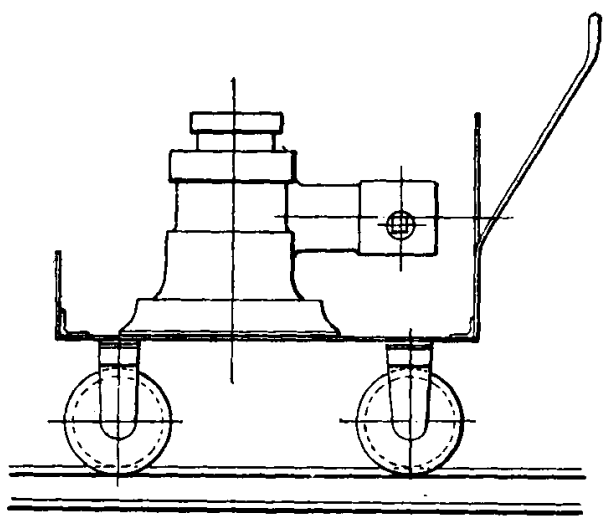

FIC. 4.

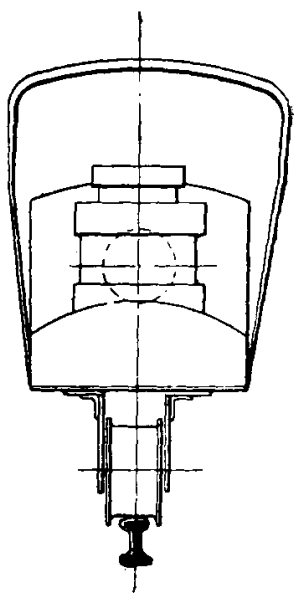

Uncoupling of Engines and Tenders.-It frequently occurs that a locomotive is so derailed that it is necessary to uncouple the engine and tender. Considerable difficulty may be experienced in the removal of the intermediate drawbar pins. For this purpose the stand and link used in conjunction with a small hydraulic jack will be found to be very effective.

Slotted Block.-Where hydraulic jacks cannot be placed directly under the frames of engines and tenders for the purpose of lifting the same, the slotted block is necessary. Often where a direct lift is possible a block of this description may be used with advantage (Figs. 5 and 6 ).

Buffer-Locked Wagons.-Buffer-locked wagons may readily be released by inserting wooden scotches tapering from 5 in. to nothing, ${ }_{5}$ in. to $\mathrm{r} 8 \mathrm{in}$. in length, and $4 \mathrm{in}$. 11 width, in front of each of the trailing wheels of the wagon. The wagon is then uncoupled and slowly drawn up over the 
scotches. By this means the buffer-locked end will be lifted a sufficient height to clear the buffers of the next wagon with which it has been buffer-locked. It sometimes happens that if the wagron is pulled up too quickly, it may, when dropping clear of the scotches, drop off the rails. A pair of ramps are inserted, and a further pull of a yard or so will soon put matters right.

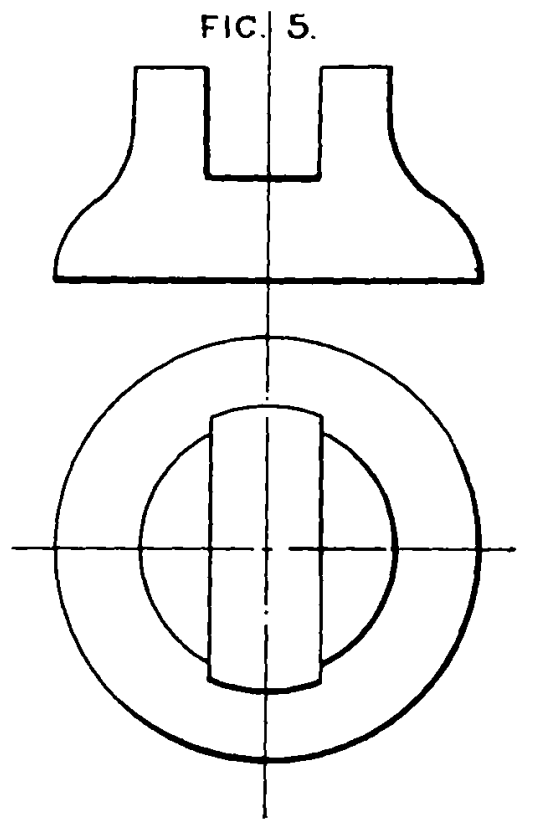

To Pull a Wagon when the Drawgear is Broken.Should the drawgear of a derailed wagon be broken, a sling chain passed round the centre of one of the axles or a double chain hooked up to the axleguards will be found to be effective substitutes.

Uncoupling of Derailed Stock.-In the case of most derailments the first task is to uncouple vehicles. It is frequently found that couplings are twisted or taut. Where locomotive power cannot be directly applied, vehicles may be drawn together by a chain fitted with hooks at each end, at the centre of which is a strong screw shackle operated by means of a ratchet and pawl. This is usually attached to the under-frames or axles of the two vehicles to be liberated. Alternatively a snatch block and cable coupled to a locomotive on in adjacent road may be made use of. If these methods 
fail, the couplings will have to be cut; this is best accomplished either by hand saws or by means of an oxy-acetylene apparatus.

Lifting of Engines, etc., by Means of Hydraulic Jacks. -Where it is necessary to rerail a locomotive by means of hydraulic jacks, one jack may be used under the centre of the buffer-beam, or two jacks-one at each end of the same. A supply of hard wood packing 3 ft. 6in. in length, and from gin. to $\mathrm{I}$ in. in width, in thicknesses varying from $2 \mathrm{in}$. to $6 \mathrm{in}$., will be found to be the most useful sizes for the purpose of

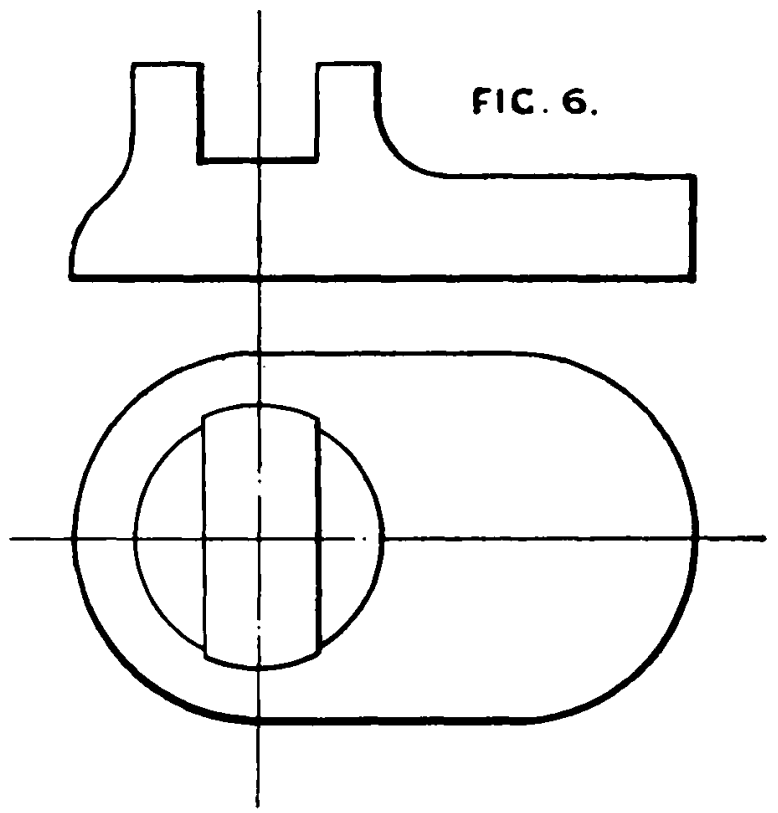

following up the jacks. Two screw jacks for following up and supporting the engine in the event of a second lift will be necessary. The most useful type of screw jack for breakdown work is one fitted with a ratchet and pawl. A jack of this type may be operated where one with drilled holes would be useless. When lifting with hydraulic jacks it is essential that the axleboxes should be well packed up between the top of the box and the frame, and between the boxes and the hornplate stays. Much unnecessary lifting is saved by this simple precaution. For the better manipulation of hydraulic jacks by two men a T-handle for pumping should be provided. Should difficulty be experienced in traversing when the 
necessary height has been obtained, assistance may be given by means of screw jacks or forcing screws placed between an adjacent rail and the tyre of the lifted wheels. A particularly useful and effective tool for this purpose is a forcing screw (Fig. 2) operated by a ratchet and pawl and attached to the stock-rail by means of links.

Broken Axleboxes on Wagons.-In the event of wagon axleboxes being broken a wooden block, having a recess to fit the journal and of such dimensions as to fit between the axleguards and under the solebar of the wagon, may be used for the purpose of moving the damaged vehicle to a siding for repairs or loading up. Similarly a bogie vehicle having one of the bogies smashed may be supported temporarily on a platelayer's bogie and blocks of packing. If a spare standard bogie is carried on the crane-runner wagon this should be made use of.

Steam Cranes.-The best type of steam crane for breakdown work is one capable of lifting a load of 35 tons at $24 \mathrm{ft}$. per minute at a radius of $20 \mathrm{ft}$. when blocked up, and of slewing that load at one revolution per minute. At that radius the total lift is $37 \mathrm{ft}$. The crane jib should be curved so that bulky packages may be lifted to the maximum height without fouling the jib. For night work, acetylene lamps of not less than 500 candle-power should be fittedone at the end of the crane jib and one at its base. Fortunate indeed is the man-in-charge who has one of these splendid appliances always to hand. There is no class of derailment which cannot be dealt with by a steam crane in very much less time than by any of the methods described earlier in this Paper. As far as possible no changes should be made in the gang appointed to work a steam crane; by constant practice each man will become thoroughly accustomed to his particular duty, general proficiency and excellent teamwork being the result. Derailed wagons are usually dealt with at one lift; a four-legged sling chain is secured about each of the buffers or behind the axleguards of the wagon. The wagon is lifted bodily, slewed to the required position and rerailed. An overturned wagon may be brought to an upright position by means of a wire cable attached to the crane hook, afterwards slung by the buffers and rerailed. A vehicle of considerable length, such as a bogie coach, is dealt with one end at a time, the bogie being secured to the under-frame by clips as before mentioned. It is usual to lift a derailed locomotive one end at a time with the crane standing on an adjacent road. The packing of axleboxes of derailed engines need not be considered when using a 
steam crane, as the time occupied for a few inches or so extra is negligible. Vehicles down embankments are usually hauled up by any convenient hold which may be obtainable, the final straightening up and slinging being done from rail level.

To deal with an overturned locomotive in a cutting, a preliminary lift is made by slinging a chain round the base of the dome and following up with hard wood packing until sufficient clearance is obtained for sling chains to be attached to the main frame and passed over the boiler to the crane hook. A lift is then made until the engine assumes an upright position, when each end is lifted alternately, slewed and rerailed. Where an engine has run down an embankment or has come to rest in a street adjacent to the line, it is customary to use two steam cranes, one at each end of the derailed engine. Both cranes lift simultaneously, and the engine is carried bodily between them and finally rerailed. This operation calls for considerable skill and great care on the part of the respective crane drivers, for if one should lift more rapidly than the other, the result might well be very serious; any sudden slip of the sling chains and one of the cranes might be easily overturned.

The chief precaution to be taken in working with a steam crane is to make quite sure that all is secure before a lift is made. The blocking girders should be drawn out at the side on which the weight is to be lifted and well packed up with hard wood packing securely wedged or held tight by means of screw jacks with large slotted heads to fit the blocking girders. At the other side the body of the crane truck should be securely shackled down to the rails with clips or dogs specially provided for the purpose.

\section{DETAILED LIST OF HEAVIER TOOLS, APPLIANCES, WOOD PACKING, ETC.}

Lighting Equipment.-The best form of lighting equipment for breakdown work during the night is by acetylene flare-lamps varying from $5^{\circ 0}$ to $\mathrm{I}$, 000 candle-power. From four to six easily portable acetylene lamps of 50 candle-power suitably placed will be found most useful for illuminating the ground underneath derailed vehicles. An acetylene hand inspection lamp for the special use of the man in charge should also be provided.

Hydraulic Jacks.- The usual complement of hydraulic 
and other jacks carried in an up-to-date tool van is generally as follows :-

Hydraulic jacks lifting 30 tons 12 in., traversing 24 in.

Hydraulic jacks lifting traversing 24 in.

Hydraulic jacks lifting traversing I 8 in.

Hydraulic jacks lifting 20 tons rain., non-traversing

Hydraulic jacks lifting i2 tons 6in., $\begin{array}{llll}\text { non-traversing } & \ldots & \ldots & \ldots\end{array} \ldots$ non-traversing

Double-screw (throwing) Pearson type $\quad \ldots \quad r$

Various screw jacks, drilled holes ... $\quad \ldots \quad 4 \quad 4$

Haley jacks (double-acting) for empty wagons

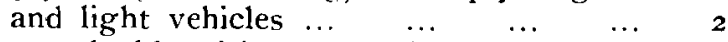

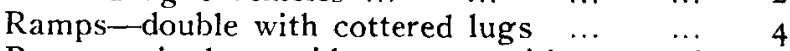

Ramps-single outside pattern with cottered $\begin{array}{lllllllll}\text { lugs } & \ldots & \ldots & \ldots & \ldots & \ldots & \ldots & 2\end{array}$

Ramps-single inside pattern with cottered lugs ...

Scrap Lengths of Rail.-An assortment of pieces varying from $\mathrm{Ift}$. to $1 \mathrm{ft}$. in length, shorter lengths predominating; a number of fishplates to be used for rough packing, etc. Several pieces of steel plate ${ }_{5} 5$ in. by r 2 in. by $\frac{1}{2}$ in. for slewing purposes.

Wire Cables and Snatch Blocks.-There should be at least two wire cables of $\mathrm{Iin}$. diameter and 6oft. in length fitted with a ring at one end and a hook at the other. Two shorter cables of from $25 \mathrm{ft}$. to 3 oft. in length and $\mathrm{rin}$. diameter similarly fitted should also be provided. Two snatch blocks ioin. and $\mathrm{I} j \mathrm{in}$. diameter respectively and fitted with either rings or hooks are necessary.

Wood Packing, etc.-A list of the most useful sizes of hard wood packing to be found in the packing van may be of interest :- An assortment of pieces $3 \mathrm{ft}$. 6in. in length, gin. in width, and varying in thickness from zin. to 6in.; two pieces each $8 \mathrm{ft}$. in length, I Iin. wide, 2 in., $3^{\text {in., }} 4$ in., and $6 \mathrm{in}$. thick respectively; six wedges $4 \mathrm{ft}$. long, 9 in. wide, tapering from 2 in. to nothing; a plentiful supply of wedges 15 in. long, gin. wide, and tapering from inn. to nothing; smaller wedges gin. long, 4in. wide, tapering from $\frac{1}{2}$ in. to nothing; several blocks 15 in. by rrin. by 6 in.; an assortment of various sized scotches and sprags. To prolong 
the life of the larger sizes of packing, a bolt passed through the width with head of bolt and nut recessed and near to each end of the piece will be found to be a preventive from splitting when in use.

CHAINS FOR LIFTING, SLINGING, DRAGGING, ETC.

Sling chains, 4 legs, length $13^{f t}$, diameter

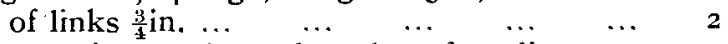

Sling chains, 4 legs, length $\mathrm{r} 2 \mathrm{ft}$, diameter of links $\frac{5}{8}$ in. ... $\quad \ldots \quad \ldots \quad \ldots \quad \ldots \quad$ I

Sling chains, 2 legs, length $\mathrm{I}_{3} \mathrm{ft}$, diameter of links $\frac{3}{4}$ in. ... $\quad \ldots \quad \ldots \quad \ldots, \quad \ldots \quad$ I

Sling chains, 2 legs, length $4 \mathrm{ft}$., diameter of links $\frac{3}{4}$ in. ... $\ldots, \quad \ldots \quad \ldots, \ldots, \quad$ I

Sling chains, 2 legs, length $5 \mathrm{ft}$, diameter of links $\frac{3}{4}$ in. ... $\quad \ldots \quad \ldots \quad \ldots, \ldots, \quad$ I

Single chains, ring and hook, length $4 \mathrm{ft}$. 6in., diameter of links $\frac{s}{4}$ in. $\ldots \quad \ldots \quad \ldots$

Single chains, ring and hook, length r $6 \mathrm{ft}$., diameter of links 3 in. $\quad \ldots \quad \ldots \quad \ldots \quad \ldots \quad$ I

Single chains, ring and hook, length $12 \mathrm{ft}$., diameter of links $\frac{3}{4}$ in. ... ... ...

Drag chains of various lengths from roft. to $25 \mathrm{ft}$., with links $\frac{5}{8}$ in. to $\frac{7}{8}$ in. diameter, and fitted either with ring and hook or two $\begin{array}{llllllll}\text { hooks } & \ldots & \ldots & \ldots & \ldots & \ldots & \text { ro }\end{array}$

Short coupling chains, 3 links and 2 hooks, $\mathrm{I} i \mathrm{in}$. links $\ldots \ldots \ldots$
assortment of various short sling chains

The Author hopes that the information submitted in this Paper will be of value, not only to those who are provided with complete facilities for dealing with derailments, but also, and particularly, to those who, for instance, have to accomplish rerailments in the absence of modern highcapacity cranes.

\section{DISCUSSION.}

Mr. W. Paterson: I am confident that Mr. Moore's contribution this evening will be valued, not only by those connected with the operating of the congested railways in this country, but also by those who have to deal with breakdown work in countries abroad, where the facilities may happen to be less modern and complete than they are here.

To the juniors in the profession the catalogue of appliances cnumerated in this Paper will be exceedingly 
useful. Personally, I should have esteemed very highly such a list, if it had been available for me in the early part of my career.

In reference to head-on collisions, it would be very interesting to see statistics showing the results in cases where steel coaches were involved, and to compare these with the results in cases where ordinary type coaches were in collision. Perhaps Mr. Moore can give information on this point.

American reports of violent head-on collisions between steel coaches crowded with passengers have been remarkable for the low percentage of fatalities and for the comparatively slight damage to the rolling stock.

The provision of adequate lifting appliances is absolutely essential, and the type, location and operating zone of the steam travelling cranes should be carefully considered.

It is equally important that the training of picked men for breakdown work should be provided for, in view of the fact that specialists are demanded by the very nature of the work.

Mr. Moore's classification of the causes of railway accidents is distinctly interesting, and he has very successiully tabulated the methods of dealing with accidents.

Proper emphasis is placed upon the importance of system, both in regard to the method of tackling the work of rerailment, and also the arrangements of the equipment of the breakdown train.

With much of the equipment described I am familiar, and the Author has not over-estimated its value and utility.

It would be interesting to hear the comments of the permanent way engineers upon Mr. Moore's advocacy of the methods of ramping and dragging. Most of us have heard protests against the adoption of such methods of rerailment, but we have to remember that time is of supreme importance and the most expeditious methods of clearing the line have to be adopted even if that involves rejection of the suggestions of those who have an extreme respect for a few rail chairs.

In this Paper the type of ramps to be used and the design and strength of same have, I am glad to note, been given more than the usual consideration.

In my opinion it would be to the advantage of railways generally, if special commissions were appointed to thoroughly investigate the whole question of breakdown 
equipment and ensure the evolution of the best, and make it accessible to all those who are called upon to deal with derailments.

Mr. Hurt: I think one of the strongest points in the Paper is the question of the get-at-ability of tackle in a tool van. The Author drew attention to the small tools being kept in racks. I think that if he had amplified that he would have told us there was a place for everything, and everything in its place, and no spare places. Spare racks should never be seen in a tool van. The result is that a man can always tell if all his stuff is in. When you have been out on a job at night it is a great advantage for a man to be able to look round and see that every rack in the van is full up. He knows then that everything is in, and until every rack is occupied he knows that something is missing.

When pulling rehicles on the best thing is to be courteous to the permanent way representative, but my experience is you can be too courteous, and it saves time sometimes not to be too courteous.

Mr. R. A. Warren: With reference to Mr. Moore's ideal breakdown train, I do not quite agree that two sixwheeled vans for the whole lot is enough. I think at any rate in a large train you want the whole space of your six-wheeled vans for tackle, and room to carry it conveniently, and in my opinion a separate riding van with cooking arrangements and separate places for the mer and superintendent is preferable.

One particular tool that Mr. Moore did not mention is a portable telephone; certainly it is not used on many jobs, but on a big one it is of great advantage, because you can get in touch with different signal boxes at either side of the accident, and save time.

Small racks in the tool van should be lettered to show their contents. A man should always be able to find what he wants easily, and if you have a stranger any time in the van, he is going to be in difficulties. In my opinion a preferable way for packing is to have a packing van, with long timbers in centre, and short ones on shelves at the ends. The rack limits the size of the pieces, and particularly where electric stock has to be dealt with, certain long timber bolsters must be carried.

The details about ramping are very interesting, and I quite agree with other speakers about the permanent way, but at the same time $I$ think you have to consider whether 
you are going to do too much damage in pulling, which will eventually cause more delay in getting traffic moving.

The crane quoted has a lift of $37 \mathrm{ft}$, at 2oft. radius; in my opinion that jib is rather longer than is useful. The crane with which $I$ have had 10 deal has a $26 \mathrm{ft}$. lift, and I have never found a job with which I was stuck. On the other hand the longer jib means more time in lifting, and on a long job that loses time; if you are working in a district where there are a lot of overhead wires, a long jib is very awkward. Then again, if you have to move, and pass under wires, the longer the $\mathrm{jib}$ is the longer time it takes to more. One point to be considered, in my opinion, with regard to a steam crane, is to get one that will lift a maximum amount free on rails, because the more you can lift without packing, the more is saved in time.

With regard to an oxy-acetylene cutter. This is certainly a very useful tool indeed for breakdowns and sheds. If you can get a man who can weld with it, you can use it very usefully in the shed. Personally, I make a great deal of use of it, and many a repair job can be done with it in a minimum of time. It saves a tremendous amount of stripping.

I was sorry the Author did not amplify his remarks $r e^{r}$ a standard bogie. Some people might think it was a carriage bogie. I presume it is one which will carry any stock on the road, and also any engine.

Mr. F. J. Hookham : The Author has made an extremely fine analysis of the problem and a good summary of the methods to be adopted, but there is one method I have seen used he did not actually touch upon. A breakdown gang I used to accompany at one time was very well trained in the method of slewing without traversing jacks. They would raise one end of the engine with ordinary hydraulic jacks standing slightly canted on packing and then, when the jack was right out would push the engine over so that in falling it would travel somewhere about a foot, whereupon they would repeat the process; and really the time saved in getting tackle together enabled them to deal with a bad derailment in a very short time. There used to be a fair amount of keen competition between this gang and the L. and N.W.R. and they could generally beat the latter company on breakdown jobs. I do not know how they would come off against the $L$, and Y.R.

We had one or two very interesting jobs; one was the case of a 3o-ton Cowans and Sheldon steam breakdown 
crane, which itself came to grief. A coal train had been derailed and the wagons had tipped down the embankment and emptied themselves of coal. The steam crane was engaged in replacing the wagons, which as they were empty were being lifted without the crane being packed up. They carelessly got hold of a wagon with some coal left in it and as a result the crane itself tipped over. They had to leave it until the week-end, meanwhile uncoupling the jib, which was lying down the embankment, and making ready. They eventually pulled the crane back on to its wheels by means of two hand winches and wire ropes, using snatchblocks secured to the track with engines over the points used as anchor.

Another smart little job which they had was recovering an engine pushed down an embankment. The engine lay over on its side with one end of the frame considerably lower than the other and the chimney sticking out over a field. This had to remain until the week-end, and while waiting a track of close laid sleepers was made to rail level. Temporary rails laid on their sides as described by the Author, were used, only instead of laying the rails on the sleepers they secured them on to the wheels so that as the engine was pulled up by the steam crane it came down on to the rails it brought with it ; then by means of another engine they hauled the engine up the temporary track on to the rails again. The whole was cleared in a matter of five to six hours.

Mr. J. N. Gresham: This Paper has been of particular interest to me, for the Author has shown us what can be done with modern appliances. During the war I served with a 12 in. railway howitzer battery, I 8 th Siege. We were only equipped with 2o-ton screw lifting jacks and with two hand traversing jacks. My experience with the latter was that owing to dirt and mud, they would never traverse when wanted. The desired result was obained by a means not mentioned by Mr. Moore. A holdfast was made of five foot pickets, to which snatchblocks were attached and the gun, having been jacked up, was pulled sideways across previously laid timber by hand. This method proved rapid and was greatly to be preferred to traversing bv means of iacks.

Mr. Mitchell : Is there any form of portable tripod with suitable beams which could be used on colonial railways instead of the steam crane of this country; an appliance with three separate legs, which could be worked by semiskilled men, and used for lifting the end of a locomotive? 
The Author: In reply to Mr. Paterson on the question of steel-bodied stock, not having any experience as to its behaviour in the event of its being subjected to the violent test of a head-on collision, I can only venture an opinion. I should not hesitate to say that the tendency to damage by its use would be considerably less. Apart from the damage caused by collision the risk of fire would be overcome to a great extent. Telescoping of such stock would be an infrequent occurrence. A number of experiments with steel-bodied stock have been carried out in this country and in America. From information I have been able to gather, these tests have proved the steel-bodied coach to be in every way superior to the wooden structure. Mr. Paterson considers that some of the more forcible means of dealing with derailments would not meet with the wholehearted approval of officials of other departments than the loco. Perhaps not, the fact remains that the man in charge of a breakdown gang has the responsibility of clearing the line and it is for him to say how that end can best be attained. A broken chair more or less cannot be considered. A waste of 30 minutes to one hour for the sake of sparing a little extra damage is a very serious matter. Time must be saved wherever possible. Damage can be repaired afterwards at leisure.

Mr. Hurt refers to the visibility and accessibility of the appliances carried in the breakdown trains. This particular point has been the subject of very close attention in the fitting up of modern breakdown trains. A few years ago when the old four-wheeled vans were more or less universally in use for breakdown trains they were fitted with deep lockers with lids. Everything that could possibly be stored in these lockers was carefully stowed away out of sight. The result was, that if any particular appliance was required it was generally found buried away at the bottom of the last lccker to be opened. After a time came the six-wheeled tool van, which gave much more room. Lockers were abolished and racks fixed to the van walls, a rack for everything and everything kept in its appointed place. This type of tool van is now standard. Anything required can be seen at a glance.

Mr. Warren does not agree with regard to the number of rehicles forming the trains. I do not consider that more than fire rehicles are necessary, especially at a depot where a steam crane is stationed. There is not 
the necessity for a large quantity of auxiliary tackle to be carried when a steam crane is available, indeed many of the appliances mentioned in the Paper are superfluous in that case. Apart from this, a train composed of a greater number of vehicles becomes unwieldy for shunting and marshalling in restricted places. The packing van can be so arranged as to provide ample accommodation for packing and tolerably comfortable quarters for the breakdown gang. Packing cages should only contain those pieces of packing most frequently required for use with hydraulic jacks. There is ample room for the large pieces to be carried clear of the packing cage. The bogie carried on the crane-runner wagon should certainly be of standard pattern, adaptable to all classes of stock. The portable telephone which is carried in all breakdown trains is a very useful appliance. The difficulty is that a lineman is required to couple it up. Unless the telephonic communications are affected no such person is available, and if required has to be specially sent for after the train has arrived at the scene of the mishap. By the time he arrives in all probability the need for the instrument is past.

Mr. Hookham refers to a method of dealing with a derailed engine or vehicle which I deliberately left out of the Paper, viz., the throwing of an engine on inclined packings. The objection to the method is that it is unsafe. It is not always possible to have the same men on a gang every time the tool van is required. The method referred to calls for considerable experience and perfect understanding amongst the men engaged on the work. Of course a certain amount of risk is taken in dealing with most derailments, but in my opinion this is perhaps about the most risky of all methods, and therefore not to be recommended. The incident mentioned by Mr. Hookham where a steam crane was overturned, justifies my remarks as to the precautions to be taken when working with any type of crane. Pack well up and make all secure before making a lift.

In reply to Mr. Gresham, I consider that the running rail is to be preferred for the attachment of a snatchblock rather than to a picket. Time would be saved by using the rail.

The tripod suggested by Mr. Mitchell would, in my opinion, be best left out of the list of tackle included in breakdown equipment. It is very unwieldy and unsafe. 